\title{
Upregulation of mGlu2 Receptors via NF- $\kappa$ B p65 Acetylation Is Involved in the Proneurogenic and Antidepressant Effects of Acetyl-L-Carnitine
}

\author{
Bruna Cuccurazzu ${ }^{1,2,4}$, Valeria Bortolotto ${ }^{1,2,4}$, Maria Maddalena Valente ${ }^{1,2}$, Federica Ubezio ${ }^{1,2}$, \\ Aleardo Koverech ${ }^{3}$, Pier Luigi Canonico ${ }^{2}$ and Mariagrazia Grilli*, ,,2 \\ 'Laboratory of Neuroplasticity and Pain, University of Piemonte Orientale "A. Avogadro", Novara, Italy; ${ }^{2}$ Department of Pharmaceutical Sciences, \\ University of Piemonte Orientale "A. Avogadro", Novara, Italy; ${ }^{3}$ University of Rome Sapienza, Rome, Italy
}

\begin{abstract}
Acetyl-L-carnitine (ALC) is a naturally occurring molecule with an important role in cellular bioenergetics and as donor of acetyl groups to proteins, including NF- $\kappa$ B p65. In humans, exogenously administered ALC has been shown to be effective in mood disturbances, with a good tolerability profile. No current information is available on the antidepressant effect of ALC in animal models of depression and on the putative mechanism involved in such effect. Here we report that ALC is a proneurogenic molecule, whose effect on neuronal differentiation of adult hippocampal neural progenitors is independent of its neuroprotective activity. The in vitro proneurogenic effects of ALC appear to be mediated by activation of the NF- $\kappa$ B pathway, and in particular by p 65 acetylation, and subsequent NF- $\kappa$ B-mediated upregulation of metabotropic glutamate receptor 2 ( $\mathrm{mGlu2}$ ) expression. When tested in vivo, chronic ALC treatment could revert depressive-like behavior caused by unpredictable chronic mild stress, a rodent model of depression with high face validity and predictivity, and its behavioral effect correlated with upregulated expression of mGlu2 receptor in hippocampi of stressed mice. Moreover, chronic, but not acute or subchronic, drug treatment significantly increased adult born neurons in hippocampi of stressed and unstressed mice. We now propose that this mechanism could be potentially involved in the antidepressant effect of ALC in humans. These results are potentially relevant from a clinical perspective, as for its high tolerability profile ALC may be ideally employed in patient subpopulations who are sensitive to the side effects associated with classical antidepressants.

Neuropsychopharmacology (2013) 38, 2220-2230; doi:I0.1038/npp.20I3.121; published online 5 June 20I3
\end{abstract}

Keywords: acetyl-L-carnitine; depression; mGlu receptors; neurogenesis; NF- $\kappa$ B

\section{INTRODUCTION}

Although the role of adult hippocampal neurogenesis remains to be fully elucidated, several studies suggest its involvement in cognitive and emotional functions (Kempermann, 2008; Aimone et al, 2011; CouillardDespres et al, 2011; Sahay et al, 2011) and its deregulation in neuropsychiatric disorders, including major depression disorder (MDD) (Hsieh and Eisch, 2010; Samuels and Hen, 2011). Based on the evidence that hippocampal neurogenesis can be downregulated by chronic stress, the hypothesis has emerged that this process may contribute to MDD pathophysiology (Pittenger and Duman, 2008; Hanson et al, 2011) and that it may be necessary for some of the effects of antidepressants in rodents (Santarelli et al, 2003; David et al, 2009) and humans (Boldrini et al, 2009). Endogenous acetyl-L-carnitine (ALC), aside from its role in cellular

* Correspondence: Professor M Grilli, Department of Pharmaceutical Sciences, Laboratory of Neuroplasticity and Pain, University of Piemonte Orientale "A. Avogadro", Via Bovio 6, 28100 Novara, Italy, Tel: +39 0321375828, Fax: +390321375821, E-mail: grill@pharm.unipmn.it ${ }^{4}$ These authors contributed equally to this work.

Received 19 October 2012; revised 8 May 20 13; accepted 9 May 20 I3; accepted article preview online 14 May 2013 bioenergetics, modulates the activity of neurotrophic factors, hormones, and neurotransmitters in nervous tissues (Jones et al, 2010). Exogenously administered ALC can readily pass the blood-brain barrier (Inano et al, 2003) and it is neuroprotective at supraphysiological concentrations (Jones et al, 2010). In addition, the antinociceptive effects of ALC were demonstrated in rodent pain models (Chiechio et al, 2006, 2009). In humans, and particularly in the elderly, the beneficial effects of ALC were observed in mood disorders (Tempesta et al, 1987; Garzya et al, 1990; Bella et al, 1990; Zanardi and Smeraldi, 2006), with an unknown mechanism of action. Surprisingly, no published studies have evaluated, in animal models, the antidepressant activity of ALC. The drug can act as a donor of acetyl groups to proteins (Pettegrew et al, 2000), including the p65 member of NF- $\kappa \mathrm{B}$ transcription factors (Chiechio et al, 2006), which are implicated in adult neurogenesis and neuroplasticity (Denis-Donini et al, 2008; Koo et al, 2010; Bonini et al, 2011; Grilli and Meneghini, 2012). Interestingly, ALC modulates gene expression of metabotropic glutamate receptor 2 (mGlu2) via NF- $\kappa \mathrm{B}$ p65 acetylation and this mechanism has been proposed for ALC-mediated analgesic effects (Chiechio et al, 2006, 2009). Here we explored the possibility that ALC may promote adult 
neurogenesis and mGlu2 upregulation via NF- $\kappa$ B pathway activation and that this mechanism may contribute to its antidepressant efficacy.

\section{MATERIALS AND METHODS}

\section{Animals}

Male 5-month-old C57B/L6J mice from Charles River Laboratories (Calco, Italy) were utilized. Protocols were reviewed and approved by the local ethical committee on animal experimental studies.

\section{Drugs}

The following drugs were used: acetyl-L-carnitine and L-carnitine (Sigma-Tau, Pomezia, Italy); LY487379 (Tocris Bioscience, Bristol, UK); LY379268 and LY341495 (Ascent Scientific, Cambridge, UK); and JSH-23, SC-514, SN-50, and SN-50 M (Calbiochem-Merck KGaA, Darmstadt, Germany).

\section{Cell Cultures and Immunocytochemical Analysis}

For adult hippocampal neural progenitor cultures, the procedure for their maintenance, differentiation, and determination of apoptotic/necrotic rate was described elsewhere (Meneghini et al, 2010). To assess proliferation, neural progenitors were cultured for $2-24-72 \mathrm{~h}$ in the presence of ALC and vehicle. Bromodeoxyuridine (BrdU; $10 \mu \mathrm{M}$ ) was added to culture medium $2 \mathrm{~h}$ before cessation of treatment and then cells were fixed with $4 \%$ PFA. For immunofluorescence analysis, anti-BrdU (1:600, Novus Biologicals, Littleton, CO), anti-MAP-2 (1:600, Chemicon, Temecula, CA), anti-nestin $(1: 3000$, Neuromics, Edina, MN), anti-GFAP (1:600, Millipore, Billerica, MA), or anti-NG2 (1:500, Abcam, Cambridge, UK) antibodies were used.

\section{Western Blot Analysis}

A total of $30 \mu \mathrm{g}$ proteins were separated onto $8-10 \%$ SDSPAGE gel. The primary antibodies used were: anti-mGlu2 (1:1000, Abcam), anti-mGlu3 (1:1000, Alomone Labs, Jerusalem, Israel), anti-PAR-1 (1:1000, Santa Cruz Biotechnology, Santa Cruz, CA), anti-Acetyl-NF- $\kappa$ B p65 (Lys310) (1:1000, Cell Signaling Technology, Danvers, MA), and anti-NF- $\kappa$ B p65 (1:1000, Santa Cruz Biotechnology). Densitometric analysis was performed by Quantity One software (Bio-Rad Laboratories), with samples normalized to $\alpha$-tubulin ( $1: 2000$, Sigma Aldrich, Milan, Italy) or $\beta$-actin signals $(1: 2000$, Sigma Aldrich).

\section{UCMS Procedure and Behavioral Assessment}

Upon arrival, C57B/L6J male mice ( $n=66,4-5$ month old) were kept in the animal facility for 2 weeks before initiating the experimental procedure. The first 8 weeks of the UCMS regimen were drug free and treatment began from week 9 of UCMS and continued up to the end of behavioral testing. Vehicle $(0.9 \% \mathrm{NaCl})$ or ALC $(100 \mathrm{mg} / \mathrm{kg})$ were administered s.c., once a day, for 3 weeks. In the first 5 days of treatment, a subgroup of mice $(n=24)$ was also given a daily dose of
BrdU ( $150 \mathrm{mg} / \mathrm{kg}$, Sigma Aldrich, i.p.). The stress regimen and behavioral analysis were applied as previously described (Koo et al, 2010; Valente et al, 2012).

\section{In Vivo Neurogenesis Studies}

For assessing the effect of drug treatment on cell proliferation, mice were treated for 21 days with ALC $(100 \mathrm{mg} / \mathrm{kg}$, s.c.) or vehicle. In the last day of treatment, mice received $\mathrm{BrdU} 150 \mathrm{mg} / \mathrm{kg}$ i.p. and were killed $2 \mathrm{~h}$ later. For acute (1 day) and subchronic (7 days) ALC treatment, mice were treated with BrdU on the first day of drug treatment and killed 21 days later. Mice were transcardially perfused and brain tissue prepared for immunofluorescence analysis with anti-BrdU (1:200; Novus Biologicals), anti-Neuronal Nuclei (NeuN; 1:150; Millipore), and anti-glial fibrillary acidic protein (GFAP; 1:100; Santa Cruz Biotechnology). Quantification of newborn hippocampal neurons and $\mathrm{BrdU}^{+}$cells was performed by modified unbiased stereology (DenisDonini et al, 2008).

\section{ALC Plasma Measurement}

Quantification of ALC plasma levels was performed in samples from naive mice treated with vehicle and ALC $100 \mathrm{mg} / \mathrm{kg}$ s.c. for 21 days ( $n=6 /$ group), as previously described (Schaevitz et al, 2012).

\section{Statistical Analysis}

Data are reported as mean $\pm S D$. In experiments with only two groups, Student's $t$-test was used. For experiments with more than two groups, data were analyzed by one-way analysis of variance (ANOVA) followed by Tukey's post hoc test, or by a two-way ANOVA (using stress and treatment as factors), followed by Bonferroni post hoc test. Statistical significance level was set for $P$-values $<0.05$.

\section{RESULTS}

\section{ALC Promotes Differentiation of Adult Hippocampal NPC Toward the Neuronal Lineage}

Nestin $^{+}$neural progenitor cells (NPCs) isolated from adult mouse hippocampi can be maintained in an undifferentiated proliferative state (Meneghini et al, 2013). Upon removal of growth factors from medium, they stop dividing and differentiate. By double immunolabeling for markers of neurons (MAP-2) and undifferentiated progenitors (nestin), the appearance of new neurons that are $\mathrm{MAP}_{-} 2^{+}$and nestin ${ }^{-}$cells can be evaluated. Under these experimental conditions, we tested the effects of ALC $(0.01-1 \mathrm{mM})$. The drug significantly increased, in a concentration-dependent manner, the percentage of MAP- $2^{+}$cells $(\mathrm{F}(5,48)=139.2$, $P<0.0001$; Figure 1a), with a maximal effect at $300 \mu \mathrm{M}$ (\% increase over vehicle-treated cells: $+148.9 \pm 22.8$ ). Exposure to $300 \mu \mathrm{M}$ ALC also produced significant reduction of $\mathrm{GFAP}^{+}$astrocytes and $\mathrm{NG}^{+}$oligodendrocyte precursors (\% decrease over vehicle-treated cells: $-47.4 \pm 8.4$ and $-31.4 \pm 4$ for $\mathrm{GFAP}^{+}$cells $(\mathrm{P}<0.001)$ and $\mathrm{NG}^{+}$cells $(\mathrm{P}<0.001)$, respectively; Figure $1 \mathrm{~b}$ and $\mathrm{c})$. In order to investigate whether ALC promoted cell survival, we 

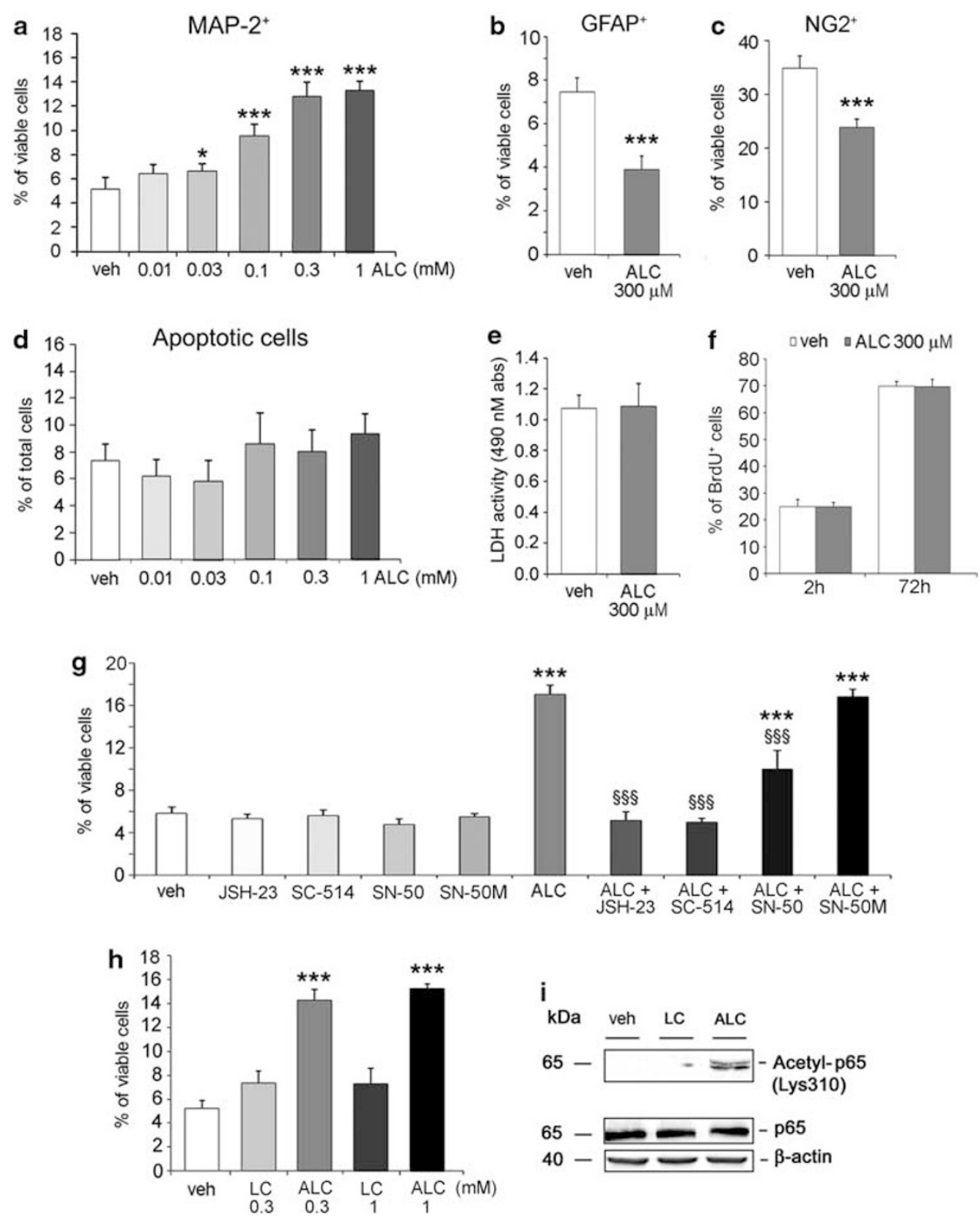

Figure I ALC proneurogenic effects on adult hippocampal neural progenitors involved activation of the NF- $\kappa$ B pathway and acetylation of p65. (a) The $24 \mathrm{~h}$ treatment with ALC $(0.0 \mathrm{I}-\mathrm{I} \mathrm{mM})$ promoted neuronal differentiation from adult hippocampal NPCs by significantly increasing the percentage of MAP$2^{+}$cells as compared with vehicle (veh). (b, c) ALC $(300 \mu \mathrm{M})$ significantly reduced the percentage of GFAP ${ }^{+}$astrocytes (b) and NG2 ${ }^{+}$oligodendrocyte precursors (c) derived from adult NPCs. (d, e) The percentage of apoptotic cells (d) and the amount of released LDH activity (e) were not significantly different in ALC- vs vehicle-treated cells. ( $f$ ) The 2- and 72-h incubation of proliferating neural progenitors with ALC $300 \mu M$ did not affect BrdU incorporation as compared with vehicle-treated cells. BrdU $(10 \mu \mathrm{M})$ was added to culture medium during the last $2 \mathrm{~h}$ of incubation. Data are expressed as

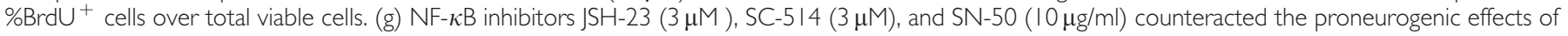
$300 \mu$ M ALC. The inactive peptide SN-50M $(10 \mu \mathrm{g} / \mathrm{ml})$ had no effect. Data are mean \pm SEM of $n=2$ experiments in triplicate for $(\mathrm{g})$ and $n=3$ experiments in triplicate for all the others. (h) The 0.3 and I mM L-carnitine (LC) produced no effect on MAP- $2^{+}$cells when compared with similar concentrations of ALC. (i) The 2-h treatment with ALC $(300 \mu \mathrm{M})$, but not LC $(300 \mu \mathrm{M})$ or vehicle, resulted in NF- $\kappa \mathrm{B}$ p 65 Lys 3 I 0 acetylation in extracts of adult NPCs. Expression levels of total $p 65$ and $\beta$-actin were also evaluated as internal controls. Data are mean \pm SD of $n=3$ experiments in triplicates. $* P<0.05$; **** $P<0.00$ I vs vehicle-treated cells, ${ }^{\$ \S \$} \mathrm{P}<0.00$ I vs ALC-treated cells. Data in ( $\mathrm{a}, \mathrm{d}, \mathrm{f}, \mathrm{g}$, and $\mathrm{h}$ ) were analyzed by one-way ANOVA followed by Tukey's post hoc test, whereas data in (b, c, and e) were analyzed by Student's t-test.

analyzed the number of apoptotic cells and the amount of LDH released by necrotic cells in culture medium in the presence of ALC or vehicle. Despite the fact that one-way ANOVA revealed a difference in the apoptotic rate $(\mathrm{F}(5,48)=6.181, P=0.0002$; Figure $1 \mathrm{~d})$, post hoc analysis confirmed no significant difference in the comparison between any ALC concentration and the vehicle group. No difference was also observed in LDH activity in vehicle- $v s$ ALC-treated cultures (Figure 1e). In addition, exposure to $300 \mu \mathrm{M}$ ALC for 2 and $72 \mathrm{~h}$ had no effect on the proliferation rate of adult hippocampal neural progenitors, compared with vehicle, as assessed by BrdU incorporation (Figure 1f). Similarly, no significant difference was reported between ALC and vehicle after $24 \mathrm{~h}$ of incubation (data not shown). 
Overall, these data demonstrated that ALC promoted neuronal differentiation of adult hippocampal NPC at the expenses of nonneuronal lineages and that neither neuroprotective nor proliferative effects were involved in drug activity in vitro.

\section{NF- $\kappa$ B Pathway Activation and p65 Acetylation Are Involved in ALC-Mediated Proneurogenic Effects}

$\mathrm{NF}-\kappa \mathrm{B}$ transcription factors are involved in CNS functions, including neuronal commitment and differentiation of adult NPC (Grilli and Memo, 1997; Denis-Donini et al, 2005, 2008; Koo et al, 2010). We then tested drugs interfering with activation of the NF- $\kappa \mathrm{B}$ pathway: JSH-23 and SN50, cellpermeable blockers of nuclear translocation of NF- $\kappa \mathrm{B}$ p 65 and p50, respectively; SC-514, a reversible inhibitor of $\mathrm{I} \kappa \mathrm{B}$ kinase 2 (IKK2). JSH-23 and SC-514 at $3 \mu \mathrm{M}$ completely abolished, whereas $10 \mu \mathrm{g} / \mathrm{ml}$ SN-50 partially counteracted $300 \mu \mathrm{M}$ ALC-induced increase of $\mathrm{MAP}-2^{+}$cells in NPC cultures $(\mathrm{F}(9,50)=223.9, P<0.0001$; Figure $1 \mathrm{~g})$. Post hoc analysis confirmed that, when applied alone, JSH-23, SC-514, and SN-50 had no effect on NPC differentiation $(5.35 \pm 0.44,5.66 \pm 0.51$, and $4.81 \pm 0.51$, respectively) as compared with vehicle (5.85 \pm 0.6 ; Figure $1 \mathrm{~g})$. Furthermore, SN50M, the mutant counterpart of SN-50, did not affect ALC activity on MAP-2 ${ }^{+}$cells (ALC + SN50M: $16.86 \pm 0.7$; $300 \mu \mathrm{M}$ ALC: $17.1 \pm 0.9$; Figure 1g). Overall, these data suggested the involvement of $\mathrm{NF}-\kappa \mathrm{B}$ signaling in the proneurogenic effects of ALC on adult hippocampal NPC.

Under similar experimental conditions, $300 \mu \mathrm{M}$ and $1 \mathrm{mM}$ L-carnitine (LC) had no effect on the generation of new neurons $(\mathrm{F}(2,18)=3.340$, NS; Figure $1 \mathrm{~h})$, unlike similar concentrations of $\operatorname{ALC} \quad(\mathrm{F}(2,18)=322, \quad P<0.0001$; Figure 1h), suggesting that acetylation may be involved in ALC proneurogenic activity. By using an antibody against Acetyl-NF- $\kappa$ B p65 (Lys310), we demonstrated that a 2-h treatment of hippocampal NPC with $300 \mu \mathrm{M}$ ALC promoted p65 acetylation (Figure 1i). No p65 acetylation could be observed when cells were treated with either vehicle or $300 \mu \mathrm{M}$ LC (Figure 1i).

Group II mGlu Receptors, and in Particular the mGlu2 Subtype, Are Involved in ALC-Mediated Effects on Adult Hippocampal NPC

The analgesic properties of ALC have been suggested to involve drug-induced upregulation of mGlu2 receptor expression in dorsal root ganglia neurons via acetylation of NF- $\kappa \mathrm{B}$ p 65 (Chiechio et al, 2006). In our culture model, the nonselective mGlu2/3 agonist LY379268 promoted neurogenesis, as shown by a concentration-dependent increase of $\mathrm{MAP}-2^{+}$cells $(\mathrm{F}(6,56)=106.2, \quad P<0.0001$; Figure 2a), with maximal effects elicited at $10 \mu \mathrm{M}(\%$ increase over vehicle-treated cells: $+164 \pm 21.7)$. As at $\mu \mathrm{M}$ concentrations the agonist loses its selectivity for group II and may activate group I and II mGlu receptors, we then assessed whether the preferential mGlu2/3 antagonist LY341495 (0.1-7.5 nM) was able to counteract ALC proneurogenic effects on hippocampal NPC. In the presence of $300 \mu \mathrm{M}$ ALC, LY341495 caused a concentration-dependent inhibition of drug-induced increase of MAP-2 ${ }^{+}$cells $(\mathrm{F}(7,64)=94.97, \quad P<0.0001 ;$ Figure $2 \mathrm{~b})$, with maximal inhibition at $7.5 \mathrm{nM}$ (Figure 2b). Alone, $7.5 \mathrm{nM}$ LY341495 produced a statistically significant reduction in the percentage of MAP-2 ${ }^{+}$cells when compared with vehicle-treated cells (7.5 nM LY341495: 3.01 \pm 0.98 ; veh: 5.41 \pm 0.67 , $P<0.05$; Figure $2 \mathrm{~b}$ ) suggesting the presence of an endogenous glutamatergic tone. In order to dissect the functional contribution of specific group II receptor subtypes, we then tested the selective mGlu2-positive allosteric modulator (PAM), LY487379. Like ALC, the mGlu2 PAM $(0.1-10 \mu \mathrm{M})$ increased the percentage of MAP- $2^{+}$cells $(\mathrm{F}(5,48)=85.68$, $P<0.0001$; Figure 2c), with a maximal effect elicited at $1 \mu \mathrm{M}$ (\% increase over vehicle-treated cells: + 192.8 \pm 28.8 ). Representative images of MAP-2 immunolabeling experiments further supported the effects of a 24-h treatment of NPC with vehicle (Figure 2d), $300 \mu \mathrm{M}$ ALC (Figure 2e), $10 \mu \mathrm{M}$ LY379268 (Figure 2f), $1 \mu \mathrm{M}$ LY487379 (Figure 2g), $7.5 \mathrm{nM}$ LY341495 in presence of $300 \mu \mathrm{M}$ ALC (Figure $2 \mathrm{~h}$ ), or $7.5 \mathrm{nM}$ LY341495 alone (Figure 2i). We then tested whether a 24-h treatment with ALC was able to upregulate expression of mGlu2 receptors in NPC cultures under differentiating conditions (Figure 2j). Densitometric analysis demonstrated that $300 \mu \mathrm{M}$ ALC increased mGlu2 protein levels $(\mathrm{F}(3,8)=$ $11.78, P=0.0026$; Figure $2 \mathrm{j}$ ) (\% increase over vehicle-treated cells: $51 \pm 19.7$ ) and that this effect was counteracted by JSH-23, which had no effect alone. Under the same experimental conditions, ALC treatment, in the presence or absence of JSH-23, had no effect on mGlu3 protein levels $(F(3,8)=0.398$, NS; Figure 2j). Altogether, these data confirmed that ALC elicited its in vitro proneurogenic effects via NF- $\kappa$ B p65-mediated upregulation of mGlu2 expression.

\section{Chronic ALC Treatment Reverts UCMS-Induced Depressive-Like Symptoms in Adult Mice}

In rodents, unpredictable chronic mild stress (UCMS) has good face validity and predictivity (Willner et al, 1987; Mineur et al, 2006; Ibarguen-Vargas et al, 2008). A group of 22 adult male C57B/L6J mice was initially submitted to a 8-week UCMS regimen or maintained under control, nonstressful conditions. The entire procedure is schematically described in Figure 3a. Before starting, mice were analyzed for $3 \%$ sucrose preference (SP), and, as expected, they unequivocally preferred drinking sucrose over water (SP $>80 \%$ ). After 8 weeks of UCMS, one-way ANOVA revealed a significant effect on SP $(F(3,40)=31.09, P<0.0001)$. In particular, a post hoc test showed that stressed mice had significantly decreased SP values compared with their basal preference $(45 \pm 4 \%$ and $80 \pm 2 \%, P<0.001$; Figure $3 \mathrm{~b})$, whereas unstressed mice displayed no difference between basal and 8-week values (78 \pm 3 and $76 \pm 2 \%$, respectively, NS; Figure 3c). Furthermore, SP between stressed and unstressed mice was also significantly different $(45 \pm 4$ and $76 \pm 2 \%$, respectively, $P<0.001$ ). In parallel, the 8 -week UCMS period increased immobility time of stressed compared with unstressed mice both in the TST $(77 \pm 9$ and $35 \pm 5 \mathrm{~s}$, respectively, $P<0.001$; Figure $3 \mathrm{~d}$ ) and in the FST $(80 \pm 5$ and $51 \pm 6 \mathrm{~s}$, respectively, $P<0.05$; Figure $3 \mathrm{e}$ ) paradigms. Altogether, these data confirmed that UCMS elicited depressive-like symptoms in mice. Then, both UCMS and control mice were divided into two groups that were administered once daily s.c. either vehicle or ALC $(100 \mathrm{mg} / \mathrm{kg}$ ) for 21 days. Stress procedure continued to be 

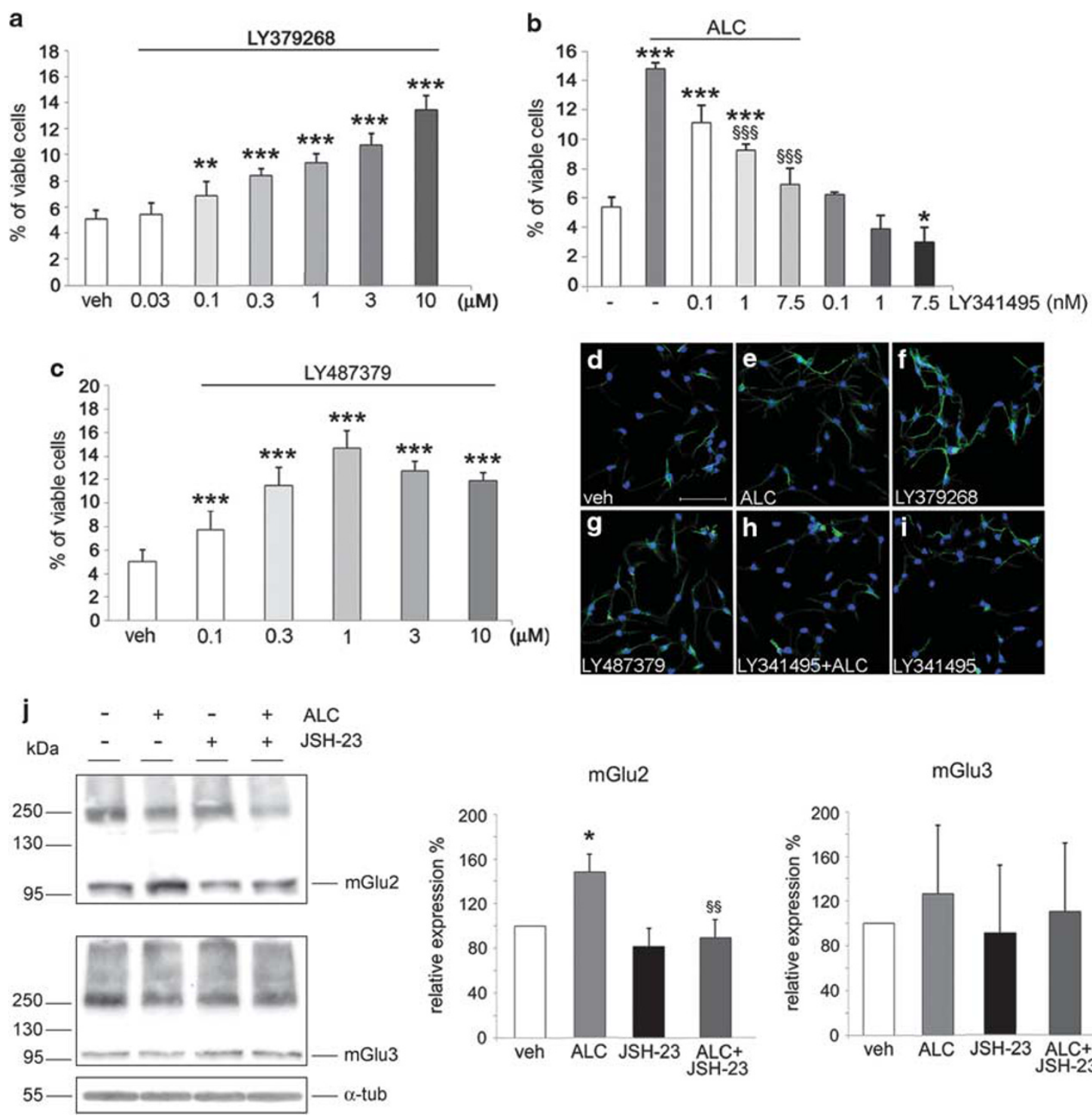

mGlu2

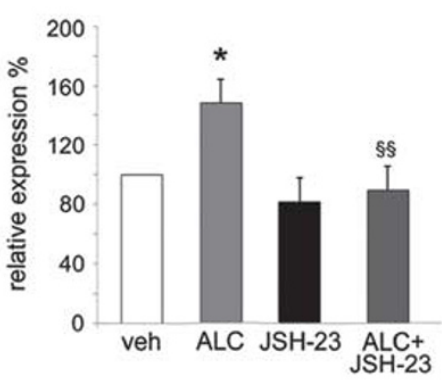

mGlu3

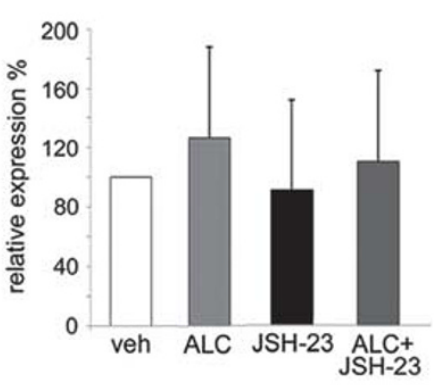

Figure 2 Group II mGlu receptors, and in particular the mGlu2 subtype, are involved in ALC proneurogenic effects. (a) The mGlu2/3 agonist LY379268 increased the percentage of MAP-2 ${ }^{+}$cells in adult NPC cultures in a concentration-dependent manner. (b) The preferential mGlu2/3 antagonist LY34I495 counteracted the effects of ALC $(300 \mu \mathrm{M})$ on MAP- $2^{+}$cells. (c) The selective mGlu2 PAM LY487379 increased the percentage of MAP-2 ${ }^{+}$cells generated from adult NPCs. (a-c) Data are mean \pm SD of $n=3$ experiments in triplicates, analyzed by one-way ANOVA followed by Tukey's post hoc test. *P $<0.05$; $* * *<0.01$; **** $P<0.001$ vs vehicle-treated cells and ${ }^{\$} \$ P<0.001$ vs ALC-treated cells. ( $\left.d-i\right)$ Representative fluorescence microscopy images of MAP-2 immunolabeling (green) in cells treated for $24 \mathrm{~h}$ with vehicle (d), $300 \mu \mathrm{M}$ ALC (e), I0 $\mathrm{MM}$ LY379268 (f), I $\mu$ M LY487379 (g), $7.5 \mathrm{nM}$ LY34I 495 + $300 \mu$ M ALC (h), and 7.5 nM LY34I 495 (i). Nuclei were counterstained with TOPRO (blue). Scale bar: $47.62 \mu \mathrm{m}$. (j) Immunoblot analysis and quantification of mGlu2 and mGlu3 protein levels in adult hippocampal NPCs treated for $24 \mathrm{~h}$ with vehicle, $3 \mu \mathrm{M} \mathrm{JSH}-23,300 \mu \mathrm{M}$ ALC in the presence of vehicle, or $3 \mu \mathrm{M} \mathrm{JSH}$-23. Compared with vehicle, ALC treatment increased mGlu2 protein levels and JSH-23 counteracted these effects. No change in mGlu3 protein levels was observed in the presence of any treatment condition. Data represent the mean \pm SD of $n=3$ experiments from different cell preparations, normalized by $\alpha$-tubulin expressions and analyzed by two-way ANOVA followed by Bonferroni post hoc test. * $P<0.05$ vs vehicle-treated cells; ${ }^{\$ \S} \mathrm{P}<0.0 \mathrm{I}$ vs ALC-treated cells

applied during drug/vehicle treatment. The drug dose was selected so to correspond to a recommended dose $(0.5 \mathrm{~g} /$ day $)$ in humans. In addition, we confirmed that the dose regimen resulted in increased plasma concentration compared with vehicle-treated mice $(297.5 \pm 28.7$ and $19.5 \pm 1.8 \mu \mathrm{M}$ in ALC- and vehicle-treated mice, $P<0.001)$. At the end of the drug administration period, mice were retested for SP and immobility time in the TST and FST. When SP was analyzed in experimental groups, a two-way ANOVA revealed a significant effect of ALC treatment $(\mathrm{F}(1,18)=20.82, P=0.0002)$ and stress $\times$ ALC interaction
$(\mathrm{F}(1,18)=11.68, P=0.0031)$ in the absence of significant effect of stress $(F(1,18)=0.844$, NS). As shown in Figure $3 b$ and $c$, chronic ALC treatment reversed UCMS-induced anhedonia (Figure $3 \mathrm{~b}$ ), with mice preferring sucrose $(76 \pm 2 \%)$ over water (Figure $3 \mathrm{~b})$. Conversely, ALC treatment had no effect on SP in unstressed mice $(66 \pm 2$ and $61 \pm 4 \%$ in ALC- and vehicle-treated control mice, respectively; Figure 3c). Importantly, chronic ALC administration had no effect on total fluid consumption in naive animals (data not shown). When we evaluated behavior in the TST, we found a significant difference of stress $(F(1,18)=9.309$, 
a
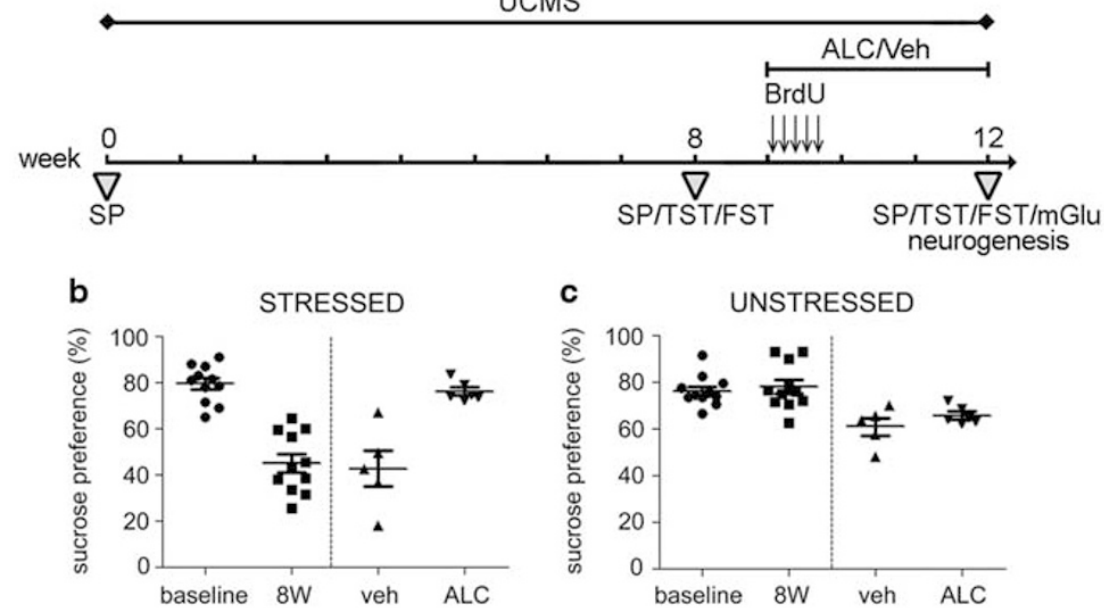

c UNSTRESSED

d

TST

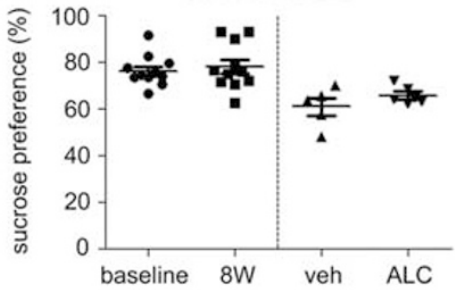
$\square \mathrm{ctrl}=\mathrm{UCMS}$

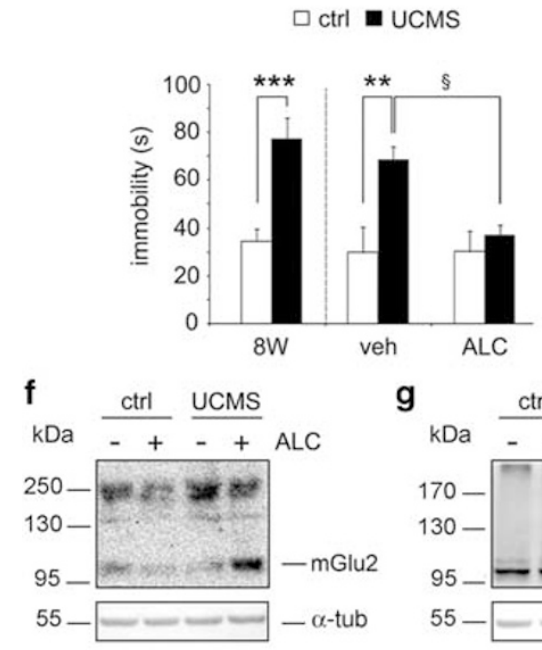

e

FST

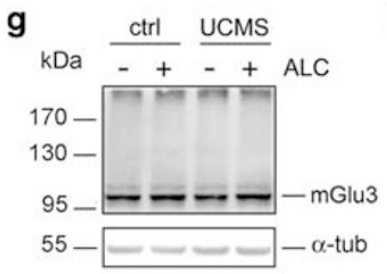

h
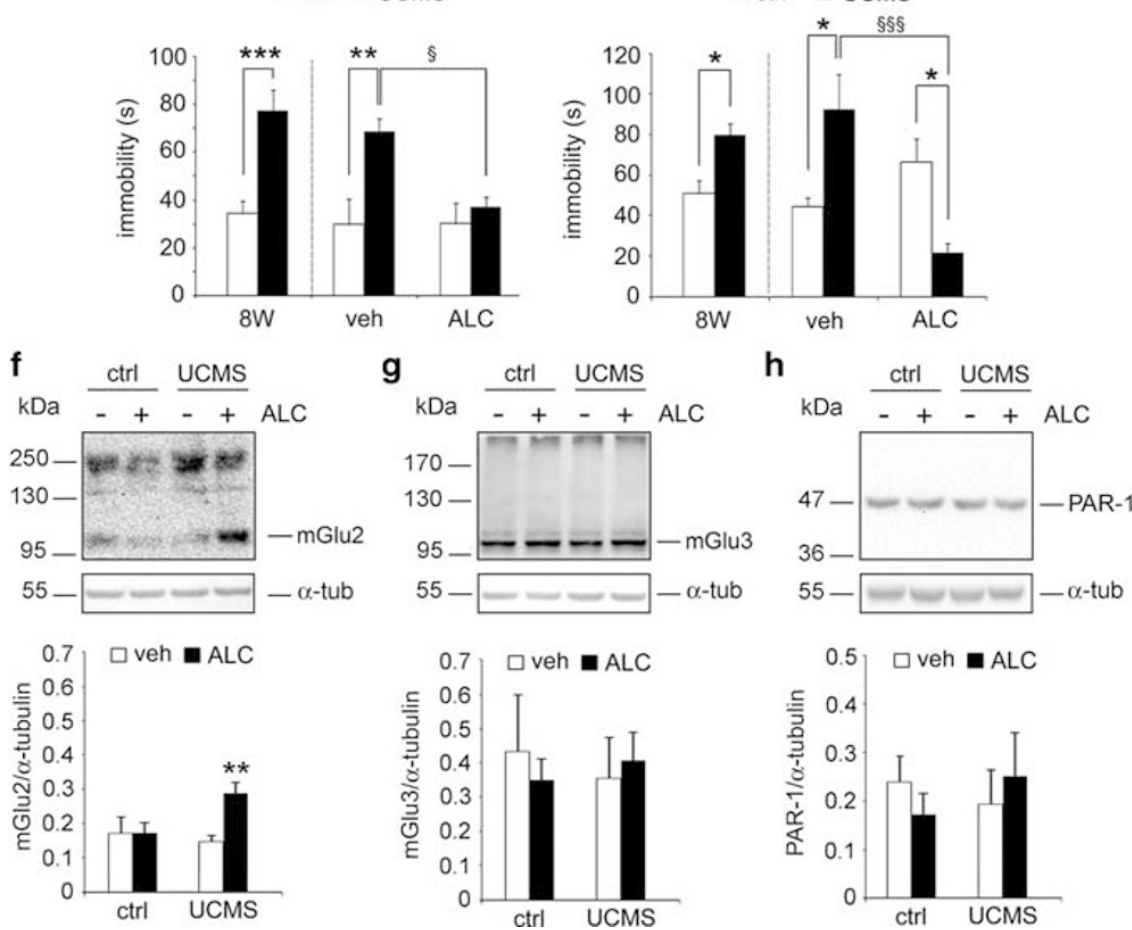

Figure 3 Chronic ALC treatment reverted UCMS-induced depressive-like behavior and upregulated mGlu2 protein levels in the hippocampi of stressed mice. (a) Schematic representation of the experimental procedure. (b, c) Sucrose preference (SP) in (b) stressed $(n=1 \mathrm{I})$ and (c) unstressed ( $n=1 \mathrm{I}$ ) mice. Mice subjected to 8-week UCMS significantly reduced SP compared with their (b) baseline values $(P<0.00 \mathrm{I})$ and with (c) unstressed mice $(P<0.00 \mathrm{I})$. (b) Chronic ALC treatment ( $100 \mathrm{mg} / \mathrm{kg}$, once a day, s.c.) reversed UCMS-induced anhedonia, with ALC-treated stressed mice $(n=6)$ displaying SP values significantly higher than vehicle-treated stressed mice $(n=5 ; P<0.00 \mathrm{I})$. (c) ALC $(n=6)$ or vehicle treatment $(n=5)$ had no effect on unstressed mice. (d, e) Behavioral analysis in the TST (d) and FST (e) following UCMS and after 21 days of saline/ALC treatment. After 8 weeks of stress, UCMS mice significantly increased time (in seconds) spent in immobility in both TST (d) and FST (e) as when compared with unstressed, control (ctrl) mice. ALC was able to revert stress-induced increase of immobility time in both TST (d) and FST (e), with ALC-treated UCMS mice immobility being significantly different from the vehicle-treated UCMS mice in both TST and FST. No significant difference was observed between vehicle- and ALC-treated unstressed mice in both TST (d) and FST (e). Data are mean \pm SD $\left(* P<0.05\right.$, *** $P<0.01$, **** $<0.00$ I, $\left.{ }^{\$} P<0.05,{ }^{\$ \$ \$} P<0.00 \mathrm{I}\right)$. (f-h) Representative experiments of immunoblot analysis of mGlu2 (f), mGlu3 (g), and PAR-I (h) levels in hippocampi of vehicle-treated unstressed, ALC-treated unstressed, vehicle-treated UCMS, and ALC-treated UCMS mice. Densitometric values are mean \pm SD of $m G l u 2 / \alpha$-tubulin, $\mathrm{mGlu} 3 / \alpha$-tubulin, and PAR- $1 / \alpha$-tubulin ratios from three independent experiments ( $n=4$ mice/group). Data were analyzed by two-way ANOVA followed by Bonferroni post hoc test. $* * P<0.0$ I vs vehicle-treated stressed mice.

$P=0.0069)$ and stress $\times$ ALC interaction $(\mathrm{F}(1,18)=4.488$, $P=0.048$ ), whereas there was no overall effect of ALC treatment $(\mathrm{F}(1,18)=4.192, P=0.055)$. Post hoc analysis revealed that ALC, but not vehicle, reverted stress-induced increase in immobility $(69 \pm 6$ and $37 \pm 4 \mathrm{~s}$ for vehiclestressed and ALC-stressed mice, respectively, $P<0.05$; Figure 3d). Similarly, in the FST, two-way ANOVA confirmed a significant effect of ALC treatment 
$(\mathrm{F}(1,18)=5.387, P=0.032)$ and stress $\times$ ALC interaction $(\mathrm{F}(1,18)=19.37, \quad P<0.0003)$, but no effect of stress $(\mathrm{F}(1,18)=0.025$, NS). The post hoc analysis showed that ALC-treated stressed mice reduced their immobility as compared with vehicle-treated stressed mice $(22 \pm 5$ and $93 \pm 17 \mathrm{~s}$, respectively, $P<0.001$; Figure $3 \mathrm{e}$ ). In addition, immobility in ALC-treated stressed mice was significantly reduced as compared with ALC-treated unstressed mice ( $22 \pm 5$ and $67 \pm 12 \mathrm{~s}$, respectively, $P<0.05$ ). On the other hand, no significant difference was observed between vehicle- and ALC-treated unstressed mice in both TST (Figure 3d) and FST (Figure 3e), whereas an increased immobility time in vehicle-stressed compared with vehicleunstressed mice was present in both TST $(69 \pm 5.62$ and $30 \pm 10.57$, respectively, $P<0.01$; Figure $3 \mathrm{~d}$ ) and FST (93 \pm 17.2 and $45 \pm 4.1$, respectively, $P<0.05$; Figure $3 e$ ). We also observed no effect of chronic ALC administration on body weight in unstressed or stressed mice (data not shown). Altogether, these data demonstrated the efficacy of chronic ALC administration in reverting depressive-like symptoms induced by UCMS in adult mice.

\section{Chronic ALC Treatment Increases mGlu2 Expression and Adult-Born Neurons in Hippocampi of Stressed Adult Mice}

At the end of the entire experimental procedure, hippocampi were dissected for evaluation of $\mathrm{mGlu} 2 / 3$ protein levels. Western blot analysis demonstrated that ALC treatment significantly increased mGlu2 protein levels $(\mathrm{F}(1,8)=13.39, P=0.0064)$. ANOVA also showed a significant effect between stress $\times$ ALC interaction $(\mathrm{F}(1,8)=12.68, \quad P=0.0074)$ and stress $(\mathrm{F}(1,8)=5.581$, $P=0.04)$. On the other hand, mGlu3 protein levels were not different in analyzing either stress $\times$ ALC interaction $(\mathrm{F}(1,8)=1.05, P=0.335)$ and stress or ALC treatment. Specifically, a post hoc test revealed that mGlu2 and mGlu3 expression levels in vehicle-treated control and UCMS mice were not significantly different (Figure $3 \mathrm{f}$ and g). Conversely, in stressed mice, ALC treatment resulted in increased mGlu2, but not mGlu3, protein levels compared with vehicle-treated mice (\% increase: $86.6 \pm 8.8$; Figure $3 \mathrm{f}$ and g). Moreover, mGlu2 and mGlu3 expression levels were not significantly different in ALC- and vehicle-treated control mice (Figure $3 \mathrm{f}$ and g). As a negative control, we verified that ALC had no effect on the expression levels of an unrelated GPCR, PAR-1 (Figure 3h). An additional group of mice was submitted to a 8-week UCMS regimen or maintained under control conditions and stressed and unstressed mice were then divided into two groups $(n=6$ each) that were administered once daily either vehicle or ALC (100 mg/kg, s.c.) for 21 days. This time, the animals were also injected with $\mathrm{BrdU}(150 \mathrm{mg} / \mathrm{kg}$, i.p.), for the first 5 days of drug treatment. At 21 days after the last drug/vehicle injection, mice were transcardially perfused and their brains processed for quantification of newly born $\mathrm{BrdU}^{+} / \mathrm{NeuN}^{+}$/ GFAP $^{-}$neurons in the dentate gyrus. Two-way ANOVA revealed no significant difference in stress $\times$ ALC interaction $(\mathrm{F}(1,14)=1.490$, NS; Figure $4 \mathrm{a}-\mathrm{e})$ and of stress $(\mathrm{F}(1,14)=2.036$, NS), whereas a significant effect of ALC treatment was observed $(\mathrm{F}(1,14)=29.20, P<0.0001)$. The post hoc analysis confirmed a significantly increased number of newborn neurons in ALC-treated stressed mice compared with vehicle-treated stressed mice $(1403 \pm 238$ and $632 \pm 215$, respectively, $P<0.01$; Figure $4 \mathrm{c}-\mathrm{e})$. The number of new neurons was also increased in ALC-treated unstressed compared with vehicle-treated unstressed mice $(1095 \pm 299$ and $608 \pm 134, P<0.05$; Figure $4 a, b$ and e). Conversely, no significant difference was reported between vehicle-treated groups. Altogether, these data demonstrate that similar to classical antidepressants, chronic administration of ALC promotes hippocampal neurogenesis in both stressed and unstressed mice. When tested, chronic ALC treatment, compared with vehicle, had no significant effect on the proliferation rate of neural progenitors, as assessed by counting $\mathrm{BrdU}^{+}$cells in the SGZ (2291 \pm 687 and $2379 \pm 327$ in ALC and vehicle-treated mice, respectively, $P=0.77)$ and in the GCL $(2221 \pm 375$ and $2241 \pm 439$ in ALC and vehicle-treated mice respectively, $P=0.93$ ) of naive animals killed $2 \mathrm{~h}$ after administration of the thymidine analog (Figure 4f). These results suggest that the proneurogenic effects of ALC are not mediated by increased proliferation of undifferentiated neural progenitors in vivo. As antidepressants usually exert their proneurogenic effects under a chronic, but not acute or subchronic, regimen (Malberg et al, 2000), we tested the effect of 1 or 7 days of ALC (and vehicle) administration on hippocampal neurogenesis in naive adult mice ( $n=7 /$ group). A single ALC treatment had no significant effect on the number of new neurons, as compared with vehicle treatment (726 \pm 187 and $866 \pm 82$ in ALC- and vehicle-treated mice, respectively; $P=0.21$ ). Although no significant difference was also observed in the number of $\mathrm{BrdU}^{+} / \mathrm{NeuN}^{+} /$ GFAP $^{-}$cells after 7 days of ALC/vehicle treatment $(1308 \pm 401$ and $979 \pm 324$ in ALC- and vehicle-treated mice, respectively; $P=0.161$ ), a two-way ANOVA revealed a significant effect of duration of ALC treatment $(\mathrm{F}(1,17)=6.697, P=0.0192)$. In particular, a post hoc analysis confirmed an increased number of $\mathrm{BrdU}^{+}$/ $\mathrm{NeuN}^{+} / \mathrm{GFAP}^{-}$cells after 7 days compared with 1 day of ALC treatment $(P<0.05)$. No difference was observed between 1 and 7 days in vehicle-treated mice.

\section{DISCUSSION}

Several double-blind, placebo-controlled studies demonstrated that ALC treatment has beneficial effects in major depression and dystymia (Bella et al, 1990; Garzya et al, 1990; Gecele et al, 1991; Zanardi and Smeraldi, 2006). Here we show, for the first time, that ALC promotes neuronal differentiation of adult hippocampal progenitors in vitro without affecting proliferation or survival rate. Recent work demonstrated the involvement of upregulated mGlu2 gene expression in ALC-mediated analgesic activity via NF- $\kappa \mathrm{B}$ p65 acetylation (Chiechio et al, 2009). Also in our experimental model, at least in vitro, the NF- $\kappa \mathrm{B}$ pathway was responsible for mediating ALC proneurogenic effects, as interfering with its activation abolished drug activity. More specifically, ALC resulted in acetylation of p65 at Lys(310) in NPC cultures. Moreover, ALC treatment of hippocampal NPC resulted in a significant upregulation of mGlu2 protein levels and this effect was abolished by inhibiting p65 nuclear translocation. It is also interesting 
a

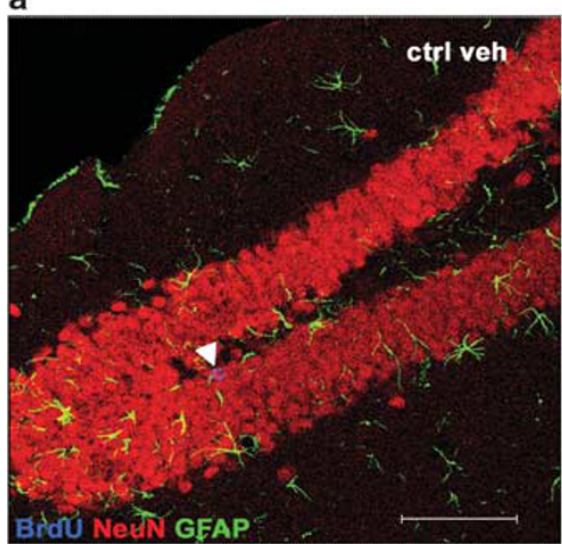

c

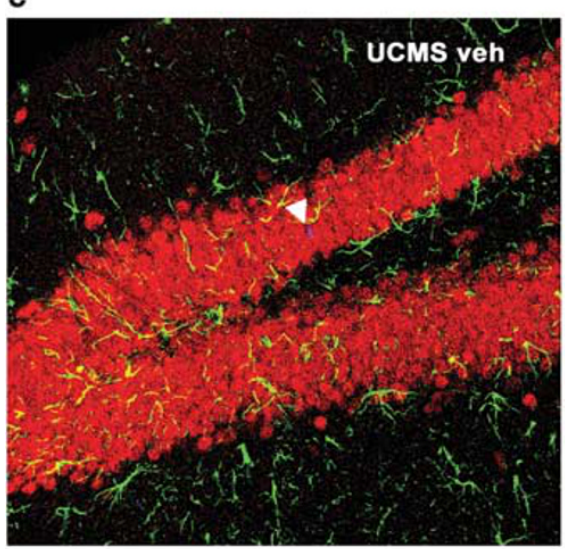

e

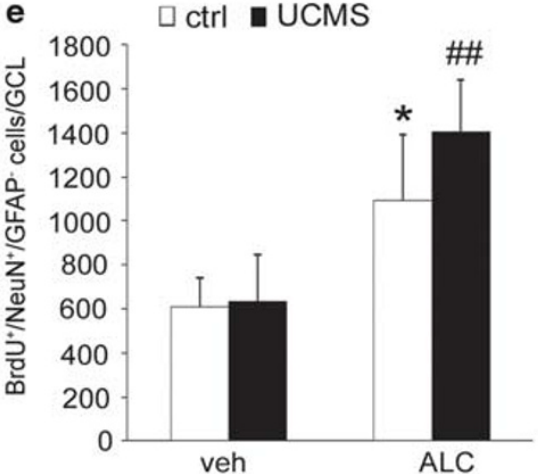

b

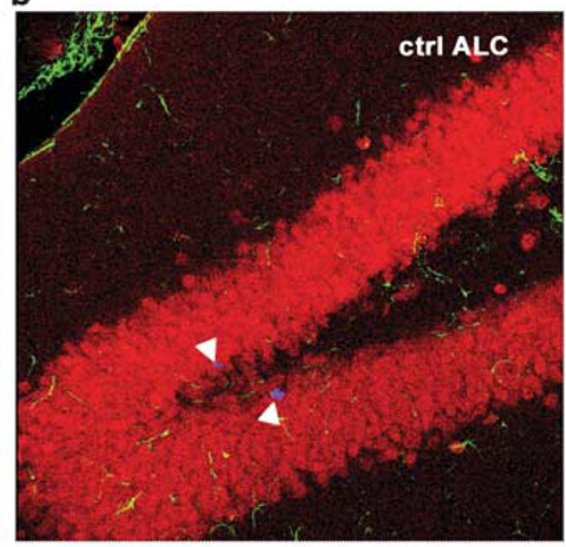

d

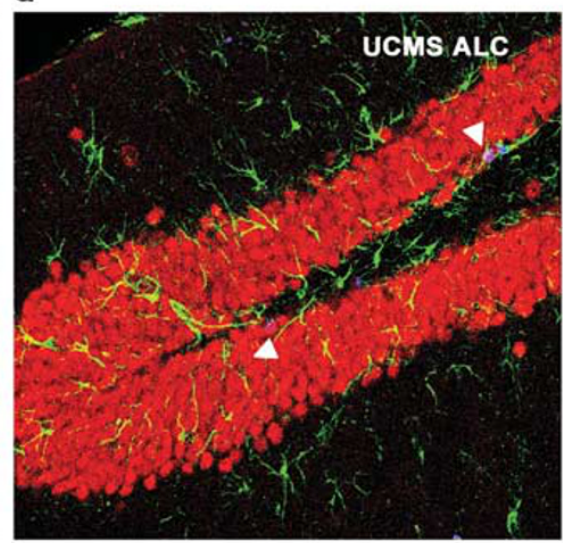

f

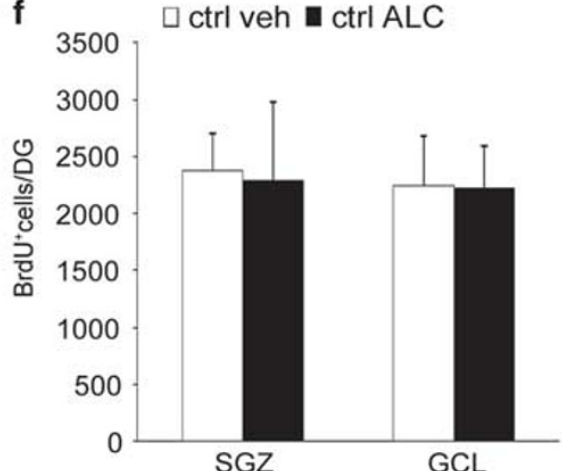

Figure 4 Chronic ALC treatment increased hippocampal neurogenesis in vivo. (a-d) Representative confocal microscopy images of immunofluorescent labeling for BrdU (blue)/NeuN (red)/GFAP (green) of hippocampal sections in control (Ctrl; a, b) and stressed (UCMS; c, d) mice subcutaneously injected with vehicle $(\mathrm{a}, \mathrm{c})$ or $100 \mathrm{mg} / \mathrm{kg} \mathrm{ALC}(\mathrm{b}, \mathrm{d})$ for $2 \mathrm{I}$ days. White arrowheads indicate $\mathrm{BrdU}^{+} / \mathrm{NeuN}^{+} / \mathrm{GFAP}^{-}$cells within the dentate gyrus. Scale bar: $75 \mu \mathrm{m}$. (e) Quantitative analysis of $\mathrm{BrdU}{ }^{+} / \mathrm{NeuN}^{+} / \mathrm{GFAP}^{-}$cells in stressed and unstressed mice. The number of newly born hippocampal neurons was significantly increased in the granular cell layer (GCL) of ALC-treated stressed and unstressed mice compared with vehicle-treated stressed and unstressed mice, respectively. Data are expressed as mean \pm SD of $n=7$ mice/group, and were analyzed by two-way ANOVA followed by Bonferroni post hoc test. * $P<0.05$ vs vehicle-treated unstressed mice; ${ }^{\# \#} \mathrm{P}<0.0 \mathrm{I}$ vs vehicle-treated stressed mice. (f) Proliferation rate in the dentate gyrus of mice treated with $100 \mathrm{mg} / \mathrm{kg}$ ALC or vehicle for $2 \mathrm{I}$ days. The number of $\mathrm{BrdU}^{+}$cells in the subgranular zone (SGZ) and GCL was not significantly different in vehicle- and ALC-treated mice killed $2 \mathrm{~h}$ after BrdU administration. Data are expressed as mean $\pm \mathrm{SD}$ of $n=7$ mice/group.

that in our culture model mGlu2 activation by a selective positive allosteric modulator promoted neurogenesis, whereas a preferential mGlu2/3 antagonist counteracted ALC-mediated proneurogenic effects. We are aware of the interpretative limitations of data generated by single mGlu ligands, as the distinct functions of mGlu2 and mGlu3 are not fully understood. For this reason, even if we did not observe significant effects of ALC on mGlu3 protein levels, at present we cannot exclude that this receptor subtype, which has been shown to be functionally expressed by adult NPC (Di Giorgi-Gerevini et al, 2005; Ciceroni et al, 2010), may also be involved. We also proved that chronic ALC reverted depressive-like behavior in a predictive animal model. Importantly, the utilized dose corresponds to the lowest recommended dose in humans ( $0.5 \mathrm{~g} /$ day) (ReaganShaw et al, 2008). Furthermore, this dose regimen effectively increased plasma levels of ALC in chronically treated mice, as previously shown (Schaevitz et al, 2012). We also 
demonstrated that chronic ALC treatment correlated with increased mGlu2 protein levels in the hippocampi of stressed but not unstressed mice. The role of group II mGlu receptors in depression is currently debated, as both mGlu2/3 agonists and antagonists can produce antidepressive effects in rodent models (Chaki et al, 2013). This apparent paradox could in part rely on the fact that mGlu2/3 subtypes may play different functions and/or may be differentially (de)regulated in depressive disorders. Although at present we have no information as to where mGlu2 upregulation may affect in the hippocampal circuit, it is known that these receptors are in the preterminal regions of perforant pathway axons and mossy fibers, where they have little effect on glutamate release under normal conditions but they may potentiate a negative feedback control under conditions of excessive glutamate release, which is associated with depression (Bonanno et al, 2005; Sanacora et al, 2008). Interestingly, THIIC, a novel potent and selective allosteric modulator of mGlu2, recently demonstrated robust antidepressant properties in vivo (Fell et al, 2011), suggesting a contribution of that subunit to the pathophysiology of depression. We also demonstrated that chronic ALC administration increased formation of adult-born neurons in the hippocampus of adult mice in vivo, a property shared by classical antidepressants. Unlike mGlu2 effects, chronic ALC treatment correlated with increased hippocampal neurogenesis in both stressed and unstressed mice. In this respect, ALC is similar to classical antidepressants that also promote neurogenesis in naive mice when chronically administered (Malberg et al, 2000). Interestingly, unlike other classical antidepressants (Santarelli et al, 2003), ALC did not affect proliferation of neural hippocampal progenitors in vitro and in vivo. Finally, like classical antidepressants, ALC did not significantly increase neurogenesis when administered acutely (1 day) or subchronically (7 days). Although no significant effects were reported between vehicle and ALC, we observed a significant increase in the number of newly generated neurons in hippocampi of 7-day ALC-treated compared with 1-day ALC-treated mice. Future experiments should investigate whether these observations may underlie a more rapid onset of proneurogenic effects of ALC compared with classical antidepressants.

The involvement of NF- $\kappa \mathrm{B}$ p65 acetylation in the proneurogenic and potentially antidepressive effects of ALC is in apparent contrast with the observation that p65 activation has been proposed to mediate decreased hippocampal neurogenesis in response to chronic stress and interleukin-1 (Koo et al, 2010). The fact that both induction and inhibition of adult neurogenesis may rely on NF- $\kappa \mathrm{B}$ p65 is likely to reflect the complexity within the $\mathrm{NF}-\kappa \mathrm{B}$ signaling pathway. Indeed, NF- $\kappa \mathrm{B}$ proteins represent a family of several transcription factors whose members, including p65, can combine to form hetero- and homodimers of different composition, which can be differentially activated in a given cell type and exert different, even opposite, functions through activation of different sets of gene targets (Grilli and Memo, 1997). In addition, little information is currently available on the contribution of p65 acetylation to the NF- $\kappa$ B-mediated transcriptional program. In this respect, in the future it will be important to identify the full set of gene targets activated by ALC in the hippocampus.
Although at present we cannot prove a causal relationship between ALC behavioral effects and drug-mediated effects on mGluR2 expression and neurogenesis in vivo, it is remarkable that ALC-mediated proneurogenic and antidepressant activity may be elicited through the mechanism mediating its analgesic effects. Interestingly, upregulation of mGlu2, via acetylation of NF- $\kappa \mathrm{B}$ p65, is also triggered by other analgesic drugs such as MS-275 and SAHA, which are histone deacetylase (HDAC) inhibitors (Chiechio et al, 2009). In addition, HDAC inhibitors are also proneurogenic (Kim et al, 2009) and elicit antidepressant-like effects (Gundersen and Blendy, 2009; Covington et al, 2009). Altogether, these and our observations would potentially imply that mGlu2 upregulation, via p65 acetylation, may also be involved in these pharmacological activities of HDAC inhibitors.

Of course, at present, we cannot exclude additional mechanisms participating in the antidepressant effects of ALC, including modulation of the glia-derived growth factor artemin (Di Cesare Mannelli et al, 2011) and increased hippocampal levels of noradrenaline (Smeland et al, 2012).

In conclusion, here we propose novel mechanisms that could be potentially involved in the antidepressant effects of ALC in humans, namely upregulation of mGlu2 levels and promotion of neurogenesis in the hippocampus, via NF- $\kappa \mathrm{B}$ p65 acetylation. The demonstration that ALC is an antidepressant in a predictive model of disease may have clinical relevance. ALC is indeed very well tolerated in humans (Thal et al, 1996, 2000) and it could be employed in patient subpopulations who are sensitive to toxicity associated with currently available antidepressants.

\section{FUNDING AND DISCLOSURE}

Over the past 3 years, PLC has received compensation as consultant from Amgen, Astra-Zeneca, Boehringer-Ingelheim, Chiesi Farmaceutici, Eisai, Grunenthal, Eli Lilly, InterMune, Pfizer, Roche, Sanofi, and Sigma Tau; and MG has received research grants from Astra Zeneca and Grunenthal. The other authors (BC, VB, MMV, FU, and AK) declare no conflict of interest.

\section{ACKNOWLEDGEMENTS}

This work was supported by grants to MG from Ministero della Istruzione, Università e Ricerca (MIUR), under the Progetti di Ricerca di Interesse Nazionale (PRIN 2007) framework. This work was financially supported, in part, by a research grant to MG from Sigma Tau Italy, which is the manufacturer of several carnitines including L-carnitine and acetyl-L-carnitine that were utilized in the study.

\section{REFERENCES}

Aimone JB, Deng W, Gage FH (2011). Resolving new memories: a critical look at the dentate gyrus, adult neurogenesis, and pattern separation. Neuron 70: 589-596.

Bella R, Biondi R, Raffaele R, Pennisi G (1990). Effect of acetyl-Lcarnitine on geriatric patients suffering from dysthymic disorders. Int J Clin Pharmacol Res 10: 355-360.

Boldrini M, Underwood MD, Hen R, Rosoklija GB, Dwork AJ, John Mann J et al (2009). Antidepressants increase neural progenitor 
cells in the human hippocampus. Neuropsychopharmacology 34: 2376-2389.

Bonanno G, Giambelli R, Raiteri L, Tiraboschi E, Zappettini S, Musazzi L et al (2005). Chronic antidepressants reduce depolarization-evoked glutamate release and protein interactions favoring formation of SNARE complex in hippocampus. J Neurosci 25: 3270-3279.

Bonini SA, Ferrari-Toninelli G, Uberti D, Montinaro M, Buizza L, Lanni C et al (2011). Nuclear factor $\kappa B$-dependent neurite remodeling is mediated by Notch pathway. J Neurosci 31: 11697-11705.

Chaki S, Ago Y, Palucha-Paniewiera A, Matrisciano F, Pilc A (2013). mGlu2/3 and mGlu5 receptors: potential targets for novel antidepressants. Neuropharmacology 66: 40-52.

Chiechio S, Copani A, De Petris L, Morales ME, Nicoletti F, Gereau RW 4th (2006). Transcriptional regulation of metabotropic glutamate receptor $2 / 3$ expression by the NF- $\kappa B$ pathway in primary dorsal root ganglia neurons: a possible mechanism for the analgesic effect of L-acetylcarnitine. Mol Pain 2: 20.

Chiechio S, Zammataro M, Morales ME, Busceti CL, Drago F, Gereau RW 4th et al (2009). Epigenetic modulation of mGlu2 receptors by histone deacetylase inhibitors in the treatment of inflammatory pain. Mol Pharmacol 75: 1014-1020.

Ciceroni C, Mosillo P, Mastrantoni E, Sale P, Ricci-Vitiani L, Biagioni F et al (2010). mGLU3 metabotropic glutamate receptors modulate the differentiation of SVZ-derived neural stem cells towards the astrocytic lineage. Glia 58: 813-822.

Couillard-Despres S, Vreys R, Aigner L, Van der Linden A (2011). In vivo monitoring of adult neurogenesis in health and disease. Front Neurosci 5: 67.

Covington HE 3rd, Maze I, LaPlant QC, Vialou VF, Ohnishi YN, Berton $\mathrm{O}$ et al (2009). Antidepressant actions of histone deacetylase inhibitors. J Neurosci 29: 11451-11460.

David DJ, Samuels BA, Rainer Q, Wang JW, Marsteller D, Mendez I et al (2009). Neurogenesis-dependent and -independent effects of fluoxetine in an animal model of anxiety/depression. Neuron 62: 479-493.

Denis-Donini S, Caprini A, Frassoni C, Grilli M (2005). Members of the NF- $\kappa \mathrm{B}$ family expressed in zones of active neurogenesis in the postnatal and adult mouse brain. Brain Res Dev Brain Res 154: 81-89.

Denis-Donini S, Dellarole A, Crociara P, Francese MT, Bortolotto $\mathrm{V}$, Quadrato $\mathrm{G}$ et al (2008). Impaired adult neurogenesis associated with short-term memory defects in NF- $\mathrm{BB}$ p50deficient mice. J Neurosci 28: 3911-3919.

Di Cesare Mannelli L, Vivoli E, Salvicchi A, Schiavone N, Koverech A, Messano M (2011). Antidepressant-like effect of artemin in mice: a mechanism for acetyl-L-carnitine activity on depression. Psychopharmacology (Berl) 218: 347-356.

Di Giorgi-Gerevini V, Melchiorri D, Battaglia G, Ricci-Vitiani L, Ciceroni C, Busceti CL et al (2005). Endogenous activation of metabotropic glutamate receptors supports the proliferation and survival of neural progenitor cells. Cell Death Differ 12: 1124-1133.

Fell MJ, Witkin JM, Falcone JF, Katner JS, Perry KW, Hart J et al (2011). $\quad \mathrm{N}$-(4-((2-(trifluoromethyl)-3-hydroxy-4-(isobutyryl) phenoxy) methyl) benzyl)-1-methyl-1H-imidazole-4-carboxamide (THIIC), a novel metabotropic glutamate 2 potentiator with potential anxiolytic/antidepressant properties: in vivo profiling suggests a link between behavioral and central nervous system neurochemical changes. J Pharmacol Exp Ther 336: 165-177.

Garzya G, Corallo D, Fiore A, Lecciso G, Petrelli G, Zotti C (1990). Evaluation of the effects of L-acetylcarnitine on senile patients suffering from depression. Drugs Exp Clin Res 16: $101-106$

Gecele M, Francesetti G, Meluzzi A (1991). Acetyl-L-Carnitine in aged subjects with major depression: clinical efficacy and effects on the circadian rhythm of cortisol. Dement Geriatr Cogn Disord 2: 333-337.

Grilli M, Memo M (1997). Transcriptional pharmacology of neurodegenerative disorders: novel venue towards neuroprotection against excitotoxicity? Mol Psychiatry 2: 192-194.

Grilli M, Meneghini V (2012). NF- $\mathrm{BB}$ proteins in adult neurogenesis: relevance for learning and memory in physiology and pathology. In: Albensi BC (ed) Transcription Factors CREB and NF- $\kappa$ B: Involvement in Synaptic Plasticity and Memory Formation. Bentham ebookpp 199-250.

Gundersen BB, Blendy JA (2009). Effects of the histone deacetylase inhibitor sodium butyrate in models of depression and anxiety. Neuropharmacology 57: 67-74.

Hanson ND, Owens MJ, Nemeroff CB (2011). Depression, antidepressants, and neurogenesis: a critical reappraisal. Neuropsychopharmacology 36: 2589-2602.

Hsieh J, Eisch AJ (2010). Epigenetics, hippocampal neurogenesis, and neuropsychiatric disorders: unraveling the genome to understand the mind. Neurobiol Dis 39: 73-84.

Ibarguen-Vargas Y, Surget A, Touma C, Palme R, Belzung C (2008). Multifaceted strain specific effects in a mouse model of depression and of antidepressant reversal. Psychoneuroendocrinology 3: 1357-1368.

Inano A, Sai Y, Nikaido H, Hasimoto N, Asano M, Tsuji A et al (2003). Acetyl-L-carnitine permeability across the blood-brain barrier and involvement of carnitine transporter OCTN2. Biopharm Drug Dispos 24: 357-365.

Jones LL, McDonald DA, Borum PR (2010). Acylcarnitines: role in brain. Prog Lipid Res 49: 61-75.

Kempermann G (2008). The neurogenic reserve hypothesis: what is adult hippocampal neurogenesis good for? Trends Neurosci 31: 163-169.

Kim HJ, Leeds P, Chuang DM (2009). The HDAC inhibitor, sodium butyrate, stimulates neurogenesis in the ischemic brain. J Neurochem 110: 1226-1240.

Koo JW, Russo SJ, Ferguson D, Nestler EJ, Duman RS (2010). Nuclear factor $-\kappa B$ is a critical mediator of stress-impaired neurogenesis and depressive behavior. Proc Natl Acad Sci USA 107: 2669-2674.

Malberg JE, Eisch AJ, Nestler EJ, Duman RS (2000). Chronic antidepressant treatment increases neurogenesis in adult rat hippocampus. J Neurosci 20: 9104-9110.

Meneghini V, Bortolotto V, Francese MT, Dellarole A, Carraro L, Terzieva $S$ et al (2013). HMGB-1 and A $\beta$-oligomers promote neuronal differentiation of adult hippocampal neural progenitors via RAGE/NF- $\kappa \mathrm{B}$ : relevance for Alzheimer's disease. J Neurosci 33: 6047-6059.

Meneghini V, Francese MT, Carraro L, Grilli M (2010). A novel role for the Receptor for Advanced Glycation End-products in neural progenitor cells derived from adult SubVentricular Zone. Mol Cell Neurosci 45: 139-150.

Mineur YS, Belzung C, Crusio WE (2006). Effects of unpredictable chronic mild stress on anxiety and depression-like behavior in mice. Behav Brain Res 175: 43-50.

Pettegrew JW, Levine J, McClure RJ (2000). Acetyl-l-carnitine physical-chemical, metabolic, and therapeutic properties: relevance for its mode of action in Alzheimer's disease and geriatric depression. Mol Psychiatry 5: 616-632.

Pittenger C, Duman RS (2008). Stress, depression, and neuroplasticity: a convergence of mechanisms. Neuropsychopharmacology 33: 88-109.

Reagan-Shaw S, Nihal M, Ahamd N (2008). Dose translation from animal to human studies revisited. FASEB J 22: 659-661.

Sahay A, Scobie KN, Hill AS, O'Carroll CM, Kheirbek MA, Burghardt NS et al (2011). Increasing adult hippocampal neurogenesis is sufficient to improve pattern separation. Nature 472: 466-470. 
Samuels BA, Hen R (2011). Neurogenesis and affective disorders. Eur J Neurosci 33: 1152-1159.

Sanacora G, Zarate CA, Krystal JH, Manji HK (2008). Targeting the glutamatergic system to develop novel, improved therapeutics for mood disorders. Nat Rev Drug Discov 7: 426-437.

Santarelli L, Saxe M, Gross C, Surget A, Battaglia F, Dulawa S et al (2003). Requirement of hippocampal neurogenesis for the behavioral effects of antidepressants. Science 301: 805-809.

Schaevitz LR, Nicolai R, Lopez CM, D'Iddio S, Iannoni E, BergerSweeney JE (2012). Acetyl-L-carnitine improves behavior and dendritic morphology in a mouse model of Rett syndrome. PLoS One 7: e51586.

Smeland OB, Meisingset TW, Borges K, Sonnewald U (2012). Chronic acetyl-L-carnitine alters brain energy metabolism and increases noradrenaline and serotonin content in healthy mice. Neurochem Int 61: 100-107.

Tempesta E, Casella L, Pirrongelli C, Janiri L, Calvani M, Ancona L (1987). L-acetylcarnitine in depressed elderly subjects. A crossover study vs placebo. Drugs Exp Clin Res 13: 417-423.
Thal LJ, Calvani M, Amato A, Carta A (2000). A 1-year controlled trial of acetyl-L-carnitine in early-onset AD. Neurology 55: 805-810.

Thal LJ, Carta A, Clarke WR, Ferris SH, Friedland RP, Petersen RC et al (1996). A 1-year multicenter placebo-controlled study of acetyl-L-carnitine in patients with Alzheimer's disease. Neurology 47: 705-711.

Valente MM, Bortolotto V, Cuccurazzu B, Ubezio F, Meneghini V, Francese MT et al (2012). $\alpha 2 \delta$ ligands act as positive modulators of adult hippocampal neurogenesis and prevent depression-like behavior induced by chronic restraint stress. Mol Pharmacol 82: 271-280.

Willner P, Towell A, Sampson D, Sophokleous S, Muscat R (1987). Reduction of sucrose preference by chronic unpredictable mild stress, and its restoration by a tricyclic antidepressant. Psychopharmacology (Berl) 93: 358-364.

Zanardi R, Smeraldi E (2006). A double-blind, randomised, controlled clinical trial of acetyl-L-carnitine vs amisulpride in the treatment of dysthymia. Eur Neuropsychopharmacol 16: 281-287. 